\title{
Об актуализации слов и словосочетаний в высказывании
}

Длительный период смешения в понятии предложения его различных аспектов, отсутствие дифференциации предложения и высказывания, использование одного термина «предложение» для обозначения двух этих сущностей привели к прочному закреплению в лингвистике не совсем адекватных интерпретаций некоторых языковых явлений. В частности, актуализированные в высказывании слова и словосочетания в большинстве известных грамматик трактуются как так называемые «односоставные предложения», которые, наравне с «двусоставными» предложениями, считаются одним из двух видов простых предложений.

Между тем, при последовательном разграничении предложения как языковой единицы и высказывания как речевой сущности, а именно так в современной лингвистике трактуются два этих понятия [14, с.42], отнесение к предложению слов типа «Winter.» и словосочетаний типа “То think of it!" и т. п., вызывает возражения.

Дело в том, что при языковой трактовке предложения оно отличается от словосочетания прежде всего определенной структурой, а именно, наличием предикативного центра (подлежащего и сказуемого), который наилучшим образом приспособлен для актуализации языковой единицы в высказывании. При этом значение предикативности заложено в самой конструкции «подлежащее + сказуемое» и не требует никаких дополнительных условий для своего обнаружения, то есть значение предикативности есть в предложении (в отличие от слова и словосочетания) при его освобождении от контекста и ситуации [21, с.164; 6, с.338].

Следует отметить, что очень часто предикативность понималась лингвистами как свойство отнесения к действительности, что, опять-таки, являлось следствием, и, вместе с тем, причиной неразличения предложения и высказывания, поскольку соотнесение с ситуацией действительности происходит только в речи, только в высказывании. Отметим, что наилучший термин для этого процесса, предложенный Ш.Балли, актуализация (а не «предикация» или «предикативность», которыми изначально называли связь предмета и признака («предиката»)). И такое соотнесение с ситуацией - актуализация - может возникнуть с помощью интонации и у слова, и у словосочетания, но при этом, становясь высказываниями, они не становятся предложениями!

Четкое языковое определение предложения было дано уже в 1966 году в первом издании «Словаря лингвистических терминов» под редакцией О.С.Ахмановой: «предложение - это двухчленный синтаксический комплекс, в котором вполне определенно выражаются два главных члена (подлежащее и сказуемое) или же, в более сложных случаях, 
группа подлежащего и группа сказуемого» [2, с.347]. Подобное определение дается и Л.С.Бархударовым: "Предложением называется языковая единица, обладающая структурой, дающей данной единице возможность употребляться в качестве минимального высказывания (речевого произведения) [4, с.141]. Однако в этом определении содержится характерная и объяснимая для лингвистики того времени неточность, поскольку давать какой-либо языковой единице “возможность употребляться в качестве минимального высказывания" может не только подлежаще-сказуемостная структура, хотя именно она наилучшим образом приспособлена для этого через передачу глаголом лица, времени и реальности/нереальности сообщаемого.

Важно, что в предложении с помощью подлежащего и сказуемого осуществляется выражение отношения признака к предмету, для чего и существует форма предложения. Именно акт соотнесения независимых предметов мысли, точнее приписывание признака предмету, называется предикацией, иногда, неточно - предикативностью [11, с.151], и в предложении подлежащее и сказуемое совместно осуществляют эту функцию. Однако, подлежащее и сказуемое - хотя и наиболее распространенный, но все же “только один из возможных способов выражения предикации" [11, c.151], и именно этот способ отличает предложение от других языковых единиц, способных передавать предикацию в менее явном виде.

Таким образом, не подлежит сомнению, что главным признаком предложения, отличающим его от слова и словосочетания, является его двусоставность, обусловленная его функцией передавать предикативное отношение. Наличие грамматической предикативности (подлежащее и сказуемое в личной форме) “делает предложение самостоятельной и

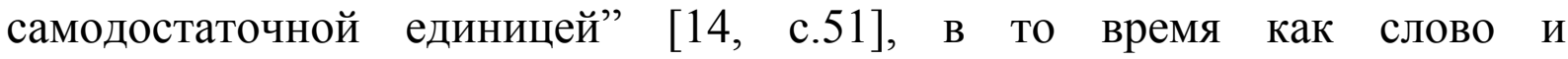
словосочетание самостоятельно, вне контекста и ситуации, предикативное отношение (приписывание признака предмету) передавать не могут, следовательно не могут быть признаны “односоставным предложением”, существование которого невозможно и по определению.

При признании нереальности “односоставного предложения" становится очевидным, что высказывание может актуализироваться и на основе словосочетаний и слов, которые не приспособлены так оптимально как предложение для передачи предикативного отношения, однако ситуация речи дает возможность и данным языковым единицам это отношение выражать. Естественно, что набор передаваемых словом и словосочетанием предикативных отношений гораздо более ограничен, как ограниченны и сами ситуации их использования в речи в качестве высказываний. В частности, значение времени в них может быть только настоящим, модальность - только реальной $[16$, с.155]. Основные предикативные признаки - бытийность и оценочность (характеризация), 
которые в ситуации могут быть осложнены эмоциональными коннотациями субъективного отношения.

Давно замечено, что среди однословных высказываний в английском языке превалируют высказывания, актуализирующие существительные в ситуациях пространственного либо временного описания [23, с.90], например: “Parkington.” (p.109), “Friday.” (p.41), “Night” (р.44). Отношение говорящего выражается как существительными, так и прилагательными: “Disaster.” (р.220); “Rude!” (р.46). Заметим, что в отсутствие контекста предикативные отношения, передаваемые этими высказываниями оказываются неясными - мы не можем точно определить, какие именно признаки приписываются предметам типа “Night”, “Parkington” - только ли бытийность или автор высказывания вкладывает в них особые характеристики. Однако в контексте такие высказывания оказываются не только абсолютно понятными, но и очень емкими, поскольку в результате их субъективного восприятия и осмысления объем декодируемой информации представляется в высокой степени индивидуализированным.

Наблюдения показывают, что словосочетания гораздо чаще актуализируются в высказывания, чем отдельные слова. Это является закономерным, поскольку словосочетание обладает большими возможностями для передачи предикативных отношений. В имеющейся выборке обращают на себя внимание многочисленные и разнообразные словосочетания существительных, например: “Rainy morning” (p.49), “An astonishing woman!” (p.89); "Oh, the cool rich linens of Mirana Hotel!” (p.90); "Glimpse of shiny skin between T-shirt and white gym shorts" (p.54); "In a princedom by the sea.” (р.9). Отметим, что предикативное отношение и конкретная семантика, помимо бытийности, и здесь могут выявлены только при знакомстве с ситуацией высказывания. В противном случае каждое из таких словосочетаний осуществляет более или менее развернутую номинацию и может представлять собой потенциально средство выражения крайне разнообразных отношений и чувств - от ненависти и недовольства до любви и восхищения.

Не менее разнообразны и глагольные словосочетания, используемые в качестве высказываний. Среди них имеются инфинитивные, например: "To hold thee tightly on a gentle knee and print on thy soft cheek a parent's kiss..." (р.70), “To have him trapped after those years!" (p.295); герундиальные: "Falling from the roof” (р.47); реже причастные: "Hidden somewhere” (р.92). Заметим, что инфинитивные словосочетания в высказывании обычно представляют собой предметную часть предикативного отношения, в то время как призначная часть выявляется из ситуации, причем наиболее распространенными являются выражения удивления, восхищения и некоторых других сильных чувств.

$$
\text { Достаточно типичными высказываниями являются }
$$

актуализированные адъективные словосочетания, например: “So blue and 
green” (р.95), “How simple!” (р.269); “Highly important” (р.235). В особых случаях они передают именно ту характеристику или отношения, которые номинируют, однако ситуация речи более четко обозначает дополнительные приращения смысла, а иногда и полностью меняет смысл словосочетаний, в частности, в случае выражения иронии.

Более редки случаи использования наречных, междометных словосочетаний, словосочетаний с числительными и других.

Примеры использования слов и словосочетаний в качестве высказываний показывают, что высказывания, построенные на их основе, выполняют в речи особую роль, отличную от высказываний, построенных на базе предложения. Многие исследователи подчеркивают их яркую экспрессивность и емкость [3; 5;10; 23 и др.]. Это, несомненно, связано с тем, что при актуализации слов и словосочетаний ситуация речи должна восполнить и материализовать то, что эксплицитно не выражено, в отличие от предложения, в котором потенциальное предикативное отношение дано на поверхностном уровне и часто может быть в основном понятно и вне контекста и ситуации.

Отметим, что в английском языке актуализированные в высказывании слова и словосочетания представляют собой типичные конструкции, образованные по законам английского языка, и выше были приведены примеры наиболее употребительных из них. Поэтому для английского языка является совершенно очевидным языковой и речевой статус описываемых единиц.

В русском языке ситуация несколько иная: в нем имеется ряд конструкций с особой семантикой (безличной, неопределенно-личной, обобщенно-личной, определенно-личной, модальной), в которых эксплицитно не выражено подлежащее (в английском языке соответствующая семантика передается двусоставными предложениями). Они традиционно описываются как односоставные, что восходит к «Синтаксису русского языка» А.А.Шахматова [см. 3; 11; 16; 18; 20 и др.].

Часть ученых выступают против такой их трактовки, настаивая на отсутствии в русском языке односоставных предложений и считая имеющиеся бесподлежащные единицы вариантами двусоставных предложений, поскольку такие предложения выполняют свое основное предназначение - сопряжение имени предмета (субъекта) и его признака (предиката). В этом случае ученые предлагают расширить в русском языке понятие подлежащего с учетом логического и семантико-синтаксического критериев, которые при этом признаются первостепенными по отношению к второстепенному критерию - формальным способа выражения субъекта и предиката $[9,12]$. Другой вариант трактовки описываемых предложений русского языка представляет их как производные от основного типа предложения - двусоставного глагольного или именного. Поэтому становится ясным, что двусоставные и односоставные предложения в русском языке не могут рассматриваться как равноправные и 
одноуровневые виды простого предложения. В соответствии с этой точкой зрения, односоставные предложения в русском языке имеют место (что связано с его флективностью и синтетическим характером), но являются вторичными, производными, и именно так и должны быть представлены в системе языка [20, с.105; 15, с.138]. Обе представленные трактовки плодотворно разрабатываются на материале русского языка в рамках теории синтаксического поля предложения.

Однако выделение и в русском языке в качестве односоставных предложений так называемых «номинативных» и «инфинитивных» предложений типа «Зима!», «Подумать только!» ошибочно, поскольку и в русском языке, как и в английском, в данном случае имеет место использование слов и словосочетаний в качестве высказываний, но не особый вид предложения, которое по определению является двусоставным.

На современном этапе развития лингвистической мысли представляется важным приведение в соответствие признаваемой всеми дихотомии «язык-речь» и конкретных ее проявлений. Такое соответствие должно найти воплощение в разграничении понятий актуализации (соотнесения языковой единицы с ситуацией действительности) и предикации (приписывания признака предмету), а также грамматической предикативности как эксплицитного способа выражения предикации предикативным центром «подлежащие + сказуемое». В свою очередь, в соответствии с этим разграничением противопоставляются предложение как двусоставная языковая единица с предикативным центром «подлежащее + сказуемое» (в отличие от других языковых единиц словосочетания и слова) и высказывание как речевая единица, в которую может воплотиться любая языковая единица (хотя оптимальная грамматическая, языковая форма для актуализации высказывания предложение).

Если последовательно придерживаться такого понимания, то «односоставные предложения» в английском языке не должны упоминаться в учебниках, а в русском языке должны рассматриваться как вторичные, производные варианты двусоставного предложения. К сожалению, несмотря на достижение лингвистами глубокого осознания и достаточно ясного описания всех вышеперечисленных понятий, изменения трактовки и определения в новейшие издания основополагающей справочной литературы и новейшие учебники по языкознанию не вносятся (см. соответствующие статьи и разделы в: 3, 5, 7, 8, 13, 17, 19 и др.). В результате каждое новое поколение лингвистов либо остается на старых недостаточно последовательных позициях и так и не переходит к следующему этапу разработки проблем, либо вынуждено заново «докапываться» до современного понимания важных лингвистических явлений, которые на самом деле уже выработаны и обоснованы. Хотелось бы надеяться, что описанное несоответствие будет преодолено в ближайшее время. 


\section{Библиографический список}

1. Алефиренко Н.Ф. Современные проблемы науки о языке. М.2005

2. Ахманова О.С. Словарь лингвистических терминов. М.1966, М.2004

3. Бабайцева В.В. Система односоставных предложений в современном русском языке. М.2004 (1968)

4. Бархударов Л.С. Структура простого предложения современного английского языка. М.1966

5. Блох М.Я. Теоретическая грамматика английского языка (на английском языке). М.2000

6. Бюлер К. Теория языка. М.1993

7. Вагина Н.С. Современный русский язык. Синтаксис. М.2003

8. Заскока С.А. Введение в языкознание. М.2005

9. Золотова Г.А. Коммуникативные аспекты русского синтаксиса. M.2003

10. Ильиш Б.А. Строй современного английского языка (на английском языке). Л.1971

11. Камчатнов А.М., Николина Н.А. Введение в языкознание. М.2002

12. Козел Н.Я К вопросу о подлежащем и субъекте//Коммуникативносмысловые параметры грамматики и текста. М.2002, с.140-143

13. Кочергина В.А. Введение в языкознание. М.2004

14. Левицкий Ю.А. Основы теории синтаксиса. М.2002

15. Лекант П.А. Что же такое подлежащее?//Коммуникативносмысловые параметры грамматики и текста. М.2002, с.135-139

16. Лекант П.А. Синтаксис простого предложения в современном русском языке. М.2004

17. Лингвистический энциклопедический словарь. 2-е издание, М.2002

18. Скобликова Е.С. Современный русский язык. Синтаксис простого предложения. М.1979

19. Современный русский язык. П/p. В.А.Белошапковой. М.2002

20. Шахматов А.А. Синтаксис русского языка М.2001

21. Шведова Н.Ю. О значении единиц разных уровней языка// Всесоюзная научная конференция по теоретическим вопросам языкознания. М.1974

22. Юрченко В.С. Простое предложение в современном русском языке. M.2005

23. Kobrina N.A., Korneyeva E.A. An Outline of Modern English Syntax. M.1965

\section{Источники примеров:}

V.Nabokov. Lolita. - N.Y.:Vintage Books.,1997 